\title{
Experimental Study of Temperature Control System for Electric Heating Furnace
}

\author{
Shengyi ZHANG ${ }^{1, a}$, Zhihui XU ${ }^{\text {b,* }}$ \\ ${ }^{1}$ School of Physics and Electronic Information Engineering, Hubei Engineering University, Xiaogan \\ 432000, China \\ a Zsyzsy6445@163.com, ${ }^{b} 346917126 @ q q . c o m$ \\ ${ }^{*}$ Corresponding author
}

Keywords: Experimental study; Temperature Controlling; PWM; PID

\begin{abstract}
Accurate and rapid control of the temperature of electric heating furnace in industrial production has important practical significance and application value. In this paper, the electric heating furnace temperature control system is designed based on C51 microcontroller, equipped with temperature sensors, AD conversion module and display module. The incremental PID algorithm is adopted to realize the temperature control of the electric heating furnace and the experimental study for the controlling accuracy and stability of this system has been done, Experiments show that: in the $0-500 \mathrm{C}^{\circ}$ range, electric heating furnace temperature control time is $60 \mathrm{~s}$, temperature control relative error of up to $1 \%$ and the stability is controlled within $2.3 \%$.
\end{abstract}

\section{Introduction}

With the development of science and technology and industrial production level, the electric heating furnace has been widely used in metallurgy, chemical, machinery and other kinds of industrial control, and occupies a pivotal position in the national economy. For such a nonlinear, large delay, large inertia, time-varying and unidirectional rising control object [1,5], it is difficult to establish accurate mathematical model, so the traditional control theory and methods depend on the precise mathematical model is difficult to achieve good ccontrol effect [6-10].

With the further development of fuzzy control, PID control and expert control system algorithm and its application in industrial control is gradually widely, especially the classical PID control algorithm also shows infinite vitality of control. Based on the C51 MCU, temperature control system of electric heating furnace is designed and the classic PID temperature control algorithm, adopted in this system, and the experimental study for the controlling accuracy and stability of this system is done.

\section{The design for the Whole System}

The system structure diagram is shown in Figure 1, the system consists of C51 microcontroller, temperature control circuit, electric heater, sensor array, amplifying and filtering circuit, a multi-channel switch, ADC module and LCD display module. The C51 microcontroller is ordinary 80C51 microcontroller for the control of the entire system, the acquisition of sensor signals and electrical heating control algorithm. The temperature control drive circuit is the bridge between the electric heating furnace and the controller. The sensor array is composed of a plurality of temperature sensors which are distributed in different places of the heating furnace so as to realize the accurate acquisition of the temperature of the whole heating furnace. The amplifier and filter circuit is used to amplify and filter the interference signal. The ADC module is used to collect the real-time temperature data of each sensor.

The input terminal of the bridge circuit to measure the furnace temperature by the thermal resistance temperature measuring element and a resistance element and converted into voltage signal to the amplifier, the signal into a $0-5 \mathrm{~V}$ voltage signal, the filter is sent to the multiplexer switch 
CD4051, multi-channel signal into the A/D converter, finally by MCU control the acquisition, SCM the digital quantity through digital filtering, scale conversion, on the one hand, LED will display the temperature; on the other hand, the value of the temperature value and the measured temperature, according to the deviation of the size of the proportional differential control (PID control), the size of the heating power solid state relay temperature control circuit and electric wire. The temperature of the control circuit, which tends to be given value and balance.

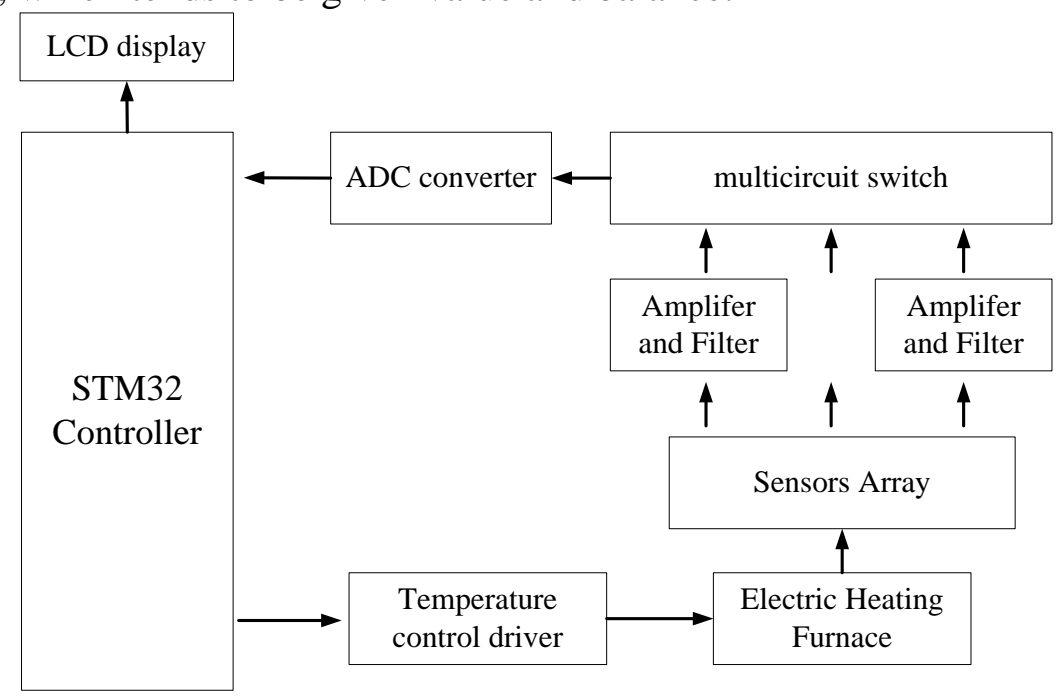

Fig. 1 diagram for the Temperature control system

\section{The Flow Chart for the Designed Software}

The execution flow of System algorithm is detailed in figure 2, after power on, the system is initialized first, initialization clock, timer, interrupt and IO peripherals, then the system enters the circular wait state. once the interrupt occurs, the microcontroller began to sample temperature, and then digital filtering, nonlinear correction in MCU inside. At last, the measured temperature can be calculated, and temperature error can be achieved compared with the current temperature, and then the MCU execute the implementation of PID control algorithm. When the temperature reaches the set value, then enter into wait state, otherwise, continue to carry out temperature sampling, the PID algorithm is implemented until the temperature reaches the set value within the allowable error range.

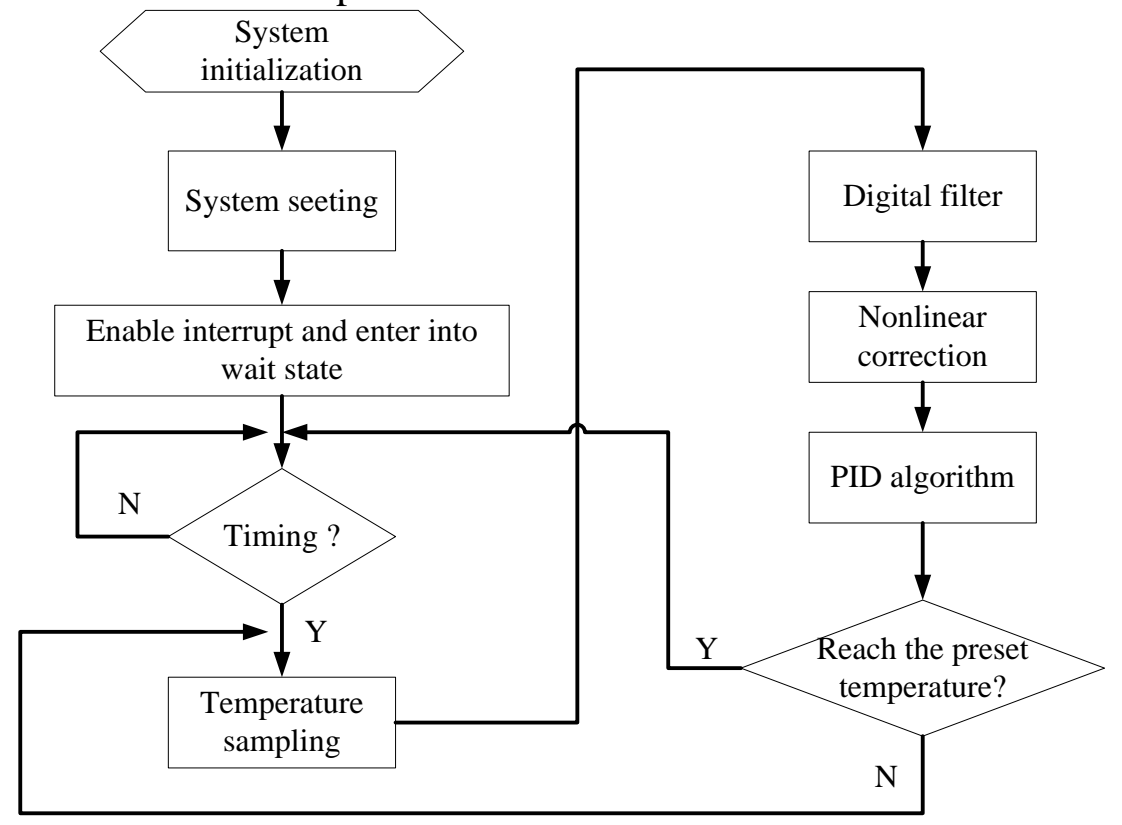

Fig. 2 the execution flow of System algorithm 


\section{Experiment and Result Analysis}

To verify the stability of the system design and master the performance of temperature control, the experiment for temperature control has been done and the recorded data is shown in Table 1 and 2. The experimental results are as follows:

(1) the temperature control precision of the whole system is very high, and the total error can be controlled within $1 \%$.

(2) in the low temperature stage, the temperature error is relatively high, can reach up to $1 \%$, while in the high temperature, with the increase of the base, the relative error is reduced.

(3) For the stability, this system is controlled within $2.3 \%$

Tab. 1 accuraty test for temperature control

\begin{tabular}{ccc}
\hline Setting value/ ${ }^{\circ} \mathrm{C}$ & Stabilized value $/{ }^{\circ} \mathrm{C}$ & Relative error \\
\hline 20 & 20.2 & $1.00 \%$ \\
50 & 49.5 & $1.00 \%$ \\
80 & 79.6 & $0.50 \%$ \\
110 & 109.5 & $0.45 \%$ \\
140 & 141.2 & $0.85 \%$ \\
170 & 170.0 & 0 \\
200 & 201.0 & $0.5 \%$ \\
250 & 251.4 & $0.56 \%$ \\
300 & 302.2 & $0.73 \%$ \\
350 & 352.8 & $0.8 \%$ \\
400 & 403 & $0.75 \%$ \\
450 & 452 & $0.44 \%$ \\
500 & 497 & $0.6 \%$ \\
\hline
\end{tabular}

Tab. 2 Stability test for temperature control

\begin{tabular}{ccc}
\hline Setting value $/{ }^{\circ} \mathrm{C}$ & Stabilized value $/{ }^{\circ} \mathrm{C}$ & Relative error \\
\hline 100 & 101.5 & $1.5 \%$ \\
100 & 102.1 & $2.1 \%$ \\
100 & 99.8 & $0.2 \%$ \\
100 & 99.2 & $0.8 \%$ \\
150 & 148.5 & $1 \%$ \\
150 & 152.4 & $1.6 \%$ \\
150 & 153.4 & $2.26 \%$ \\
150 & 148.2 & $1.2 \%$ \\
200 & 201.2 & $0.6 \%$ \\
200 & 203.1 & $1.55 \%$ \\
200 & 200.5 & $0.25 \%$ \\
200 & 198.8 & $0.6 \%$ \\
\hline
\end{tabular}

\section{Conclusions}

The temperature control of the electric heating furnace is designed and realized by using the C51 single chip microcomputer, with the sensor array, the temperature control driving circuit, the amplifying and filtering circuit, the sampling circuit of the sensor and so on. The experimental results show that the temperature control precision of the whole system is very high, the total error can be controlled within $1 \%$ and the stability is also controlled within $2.3 \%$. 


\section{Acknowledgement}

We would like to express our thanks to ours students for their valuable discussions and helps to ready for ours experiment. This work has been supported by the key project of Hubei Provincial Department of Education: D20152703

\section{References}

[1] Haijun L Y T Z L. Electronic Balance for Moisture Content Measurement Based on Optimized Time Fuzzy PID Temperature Control [J][J]. Journal of Electronic Measurement and Instrument, 2008, 4: 023.

[2] Dong Z, Su Y, Yan X. Temperature control system of the thermal analyzer based on fuzzy PID controller[C]//Hybrid Intelligent Systems, 2009. HIS'09. Ninth International Conference on. IEEE, 2009, 2: 58-61.

[3] Soyguder S, Karakose M, Alli H. Design and simulation of self-tuning PID-type fuzzy adaptive control for an expert HVAC system[J]. Expert Systems with Applications, 2009, 36(3): 4566-4573.

[4] Wittwer C T, Ririe K M, Andrew R V, et al. The LightCyclerTM: a microvolume multisample fluorimeter with rapid temperature control[J]. Biotechniques, 1997, 22(1): 176-181.

[5] Soltman D, Subramanian V. Inkjet-printed line morphologies and temperature control of the coffee ring effect[J]. Langmuir, 2008, 24(5): 2224-2231.

[6] Abilov A G, Zeybek Z, Tuzunalp O, et al. Fuzzy temperature control of industrial refineries furnaces through combined feedforward/feedback multivariable cascade systems[J]. Chemical Engineering and Processing: Process Intensification, 2002, 41(1): 87-98.

[7] Lin C J. A GA-based neural fuzzy system for temperature control[J]. Fuzzy Sets and Systems, 2004, 143(2): 311-333.

[8] Soyguder S, Alli H. An expert system for the humidity and temperature control in HVAC systems using ANFIS and optimization with Fuzzy Modeling Approach[J]. Energy and Buildings, 2009, 41(8): 814-822.

[9] Liying Z, Guoshu Z. Application of fuzzy-PID control algorithm in uniform velocity temperature control system of resistance furnace[J]. Chinese Journal of Scientific Instrument, 2008, 29(2): 405.

[10] Chen Y, Lei J, Yang X. Variable Discourse of Universe Fuzzy-PID Temperature Control System for Vacuum Smelting Based on PLC[C]. 2009 WRI Global Congress on Intelligent Systems. IEEE, 2009, 1: 541-544.

[11] Gohel V, Duan G. Conventional process for ethanol production from Indian broken rice and pearl millet. Bioprocess Biosyst Eng ,2012, 35:1297-1308

[12] Wang J, Zhang Y, Yu Q . Determination of alcohol and total acid content in Miaofu rice wine by near infrared spectroscopy. China Brewing , 2011,11:168-170 